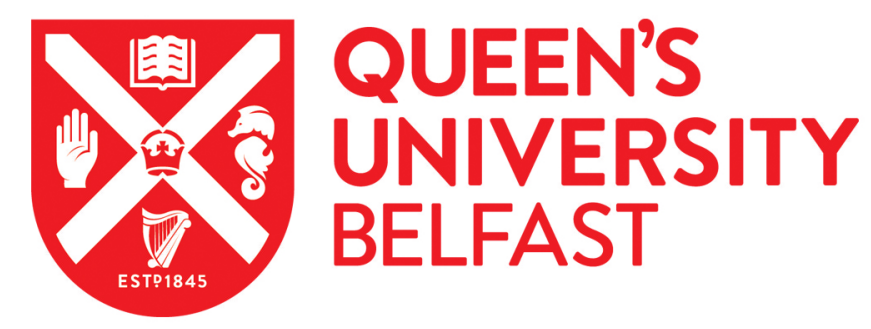

\title{
Advance care plan barriers in older patients with end-stage renal disease: A qualitative nephrologist interview study
}

O'Riordan, J., Noble, H., Kane, P. M., \& Smyth, A. (2019). Advance care plan barriers in older patients with endstage renal disease: A qualitative nephrologist interview study. BMJ Supportive and Palliative Care. https://doi.org/10.1136/bmjspcare-2018-001759

\section{Published in:}

BMJ Supportive and Palliative Care

\section{Document Version:}

Peer reviewed version

\section{Queen's University Belfast - Research Portal:}

Link to publication record in Queen's University Belfast Research Portal

\section{Publisher rights}

( 2019 Author(s) (or their employer(s)) 2019. No commercial re-use. See rights and permissions. Published by BMJ.

This work is made available online in accordance with the publisher's policies. Please refer to any applicable terms of use of the publisher.

\section{General rights}

Copyright for the publications made accessible via the Queen's University Belfast Research Portal is retained by the author(s) and / or other copyright owners and it is a condition of accessing these publications that users recognise and abide by the legal requirements associated with these rights.

Take down policy

The Research Portal is Queen's institutional repository that provides access to Queen's research output. Every effort has been made to ensure that content in the Research Portal does not infringe any person's rights, or applicable UK laws. If you discover content in the Research Portal that you believe breaches copyright or violates any law, please contact openaccess@qub.ac.uk. 


\section{A qualitative analysis of the factors which influence the clinical decision making of nephrologists managing End Stage Renal Disease in older patients in Ireland.}

\section{Background and Aims:}

Older adults, defined as $>=75$ years of age, constitute the largest group of patients diagnosed with End Stage Renal Disease ( ESRD) that commence dialysis annually; responsible for $25 \%$ of those initiating dialysis annually in the UK (ref 1). ${ }^{1}$ Many of these patients continue to endure a high symptom burden, due to the underlying condition and recovering from dialysis itself, as well the imposition of the dialysis regime (including travel to/from dialysis) (ref 2). ${ }^{2}$ Importantly, this group are also less likely to gain a significant survival advantage, predominantly due to ischaemic heart disease (ref 3$)^{3}$, as $>10 \%$ will die within three months of dialysis initiation $(\mathbf{r e f} 4,5)^{4,5}$. In addition, these patients are $50 \%$ more likely to be hospitalised. Taken together, any survival benefit of dialysis is frequently offset by more time spent in hospital and a greater likelihood of a medicalised and hospitalised death $(\text { ref } 6)^{6}$.

As the decision to initiate dialysis is not straightforward, the Renal Physicians Association (RPA) and the American Society Nephrology (ASN) issued a clinical practice guideline on the' Appropriate Initiation and Withdrawal from Dialysis', which advocates 'a shared decision making approach ensuring that patients' values and preferences play a prominent role.' Furthermore, it recommends facilitating 'advance care planning (ACP) to help the patient understand his/her condition, identify his/her goals and prepare for the decisions that may have to be made as the condition progresses over time..$^{7}$ (ref 7). Despite this, few older adults with advanced kidney disease engage in appropriate advance care planning ${ }^{13,17}$, and these patients possess a low level of awareness of prognosis (ref 9) ${ }^{9}$. As a result, they often face medically intensive end of life scenarios focused on the prolongation of life, rather than quality of life (ref 10 $)^{10}$.

Factors influencing the clinical decision among nephrologists regarding older adults with advanced kidney disease is under researched. We conducted qualitative, semi structured interviews with nephrologists to-explored with nephrologists the factors that influence the choice between RRT or conservative management in this population. We explored the perceived barriers to conservative management, nephrologists' engagement in advance care planning, factors prompting consideration of dialysis withdrawal and nephrologists approach to end of life care.

\section{Methods:}

This qualitative study used semi structured interviews. The interview topic guide was informed by a literature review of the management of ESRD in elderly patients and patient centred care literature review undertaken by the lead researcher. The interview topic guide was then reviewed by two supervisors and one collaborator.

Nephrologists employed in the Republic of Ireland between September 2017 and February 2018 were invited to participate in the study. Ethical Approval was obtained Committee at Galway University Hospitals.

First, five nephrologists working at the same clinical site were invited, by email, to participate in a focus group to ensure that the interview questions generated information pertinent to the research question. Subsequently, nephrologists at other sites throughout the Republic of Ireland were invited by email to participate in a recorded telephone interview. Nephrologists provided electronic written consent via return email. The objective of the study was presented and nephrologists were asked to 
consider the following areas of their clinical practice prior to conducting the interview; factors influencing their choice of either conservative management or dialysis for patients aged 75 years of age and over with ESRD; factors prompting consideration of dialysis withdrawal; their understanding of patients' priorities for their care; their engagement in advance care planning and specifically end of life care with patients; their perception of the role of palliative care in ESRD in elderly patients and perceived barriers to palliative care referral.

Each interview recording was transcribed verbatim by the lead researcher, anonymised and imported into Nvivo Pro 11 software for qualitative analysis. Using thematic analysis, each interview, including the focus group, was analysed and coded line by line; the extracts were organised into basic themes and any coded data from later transcripts which did not fit into pre-existing basic themes was coded under a new relevant basic theme. Further analysis of all collected data permitted identification of organising themes. Interviewing ceased when there were no further responses from nephrologists invited to participate; thematic saturation had also-occurred at this point. Organising themes were analysed using spider diagrams-and this resultinged in the identification of 4 global themes.

\section{Results:}

Thirty seven nephrologists were invited to participate; twenty three agreed to participate and twenty nephrologists took part; the response rate was 54\%. Five nephrologists participated in a face to face interview as part of a focus group; the remaining fifteen nephrologists were interviewed individually by telephone, with an average duration of 22.3 minutes. The majority of nephrologists were male, of Irish nationality and with more than 20years experience after medical school graduation (Table 1). Many had completed international fellowships as part of clinical training and all were working in a public or mixed public/private work environment. Although all had local access to palliative care services, only $25 \%$ had a designated low clearance clinic.

Commented [KK2]: Reference thematic analysis and check Commented [RO3]: Explain in sentence what happens at this clinic

Four major themes were identified:

1) Poor levels of engagement in advance care planning

2) Training deficits contribute to difficulties communicating with patients

3) Nephrologists lack confidence in Conservative Management

4) Nephrologists struggle with end of life care

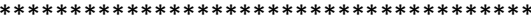

\section{1) Poor levels of engagement in Advance Care Planning (ACP):}

\section{Poor prognostic awareness amongst patients:}

Nephrologists acknowledged the importance of discussing treatment options for ESRD with older patients whose degree of renal failure is not imminently life threatening. However, frequently nephrologists avoid discussing prognosis with patients for fear of upsetting them and jeopardizing the doctor: patient relationship.
Commented [RO4]: I wouldn't have sub headings in just one theme 
'Yeah, I actually am at fault of not doing that even when people start on dialysis..... that is something that I perhaps am not good on, just telling people that this is virtually a pretty serious illness, dialysis is not a magic bullet, your life expectancy is drastically reduced (4)

'I think that when patients start dialysis we should more talk about where it's all going to end..'(6)

One nephrologist reported that colleagues disapproved of engaging patients in discussion about prognosis and others Two nephrologists justified offering dialysis to older patients by highlighting those patients whose prognosis on dialysis had exceeded expectation.

$|A m|$, with my own patients I do (discuss prognosis) but the problem is that a lot of the patients belong to colleagues who don't approve of that am so I need to be... and colleagues don't approve of sort of having any discussion what so ever.'(5)

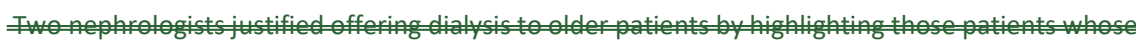
prognosison dialysis had exceded expectation.

='... when patients are on dialysis, to talk about prognosis, am I don't know, I think I would try and talk about expectation but we tend to not talk about prognosis because on the one hand we have patients who are on dialysis for 13 years yet the statistics all say it's much, much worse than that.... our living experience is different....i don't think we trust the statistics because what we are experiencing is very different..'(14)

\section{Poor levels of Health Literacy}

Many nephrologists report that older patients with ESRD are ill informed about their disease and what dialysis entails and that poor health literacy levels among patients contributes to unrealistic expectations.

$\div$

'Also the patients don't come in veryeducated about dialysis and chronic kidney disease. I do clinics in the US where people had to come down and watch a video about dialysis. So they came in you know with a little bit more insight am than people in Ireland tend to '(1)

One nephrologist remarked that poor health literacy levels among patients will contribute to unrealistic expectations.

..'because if a patient isn't well informed about what they're facing into going into dialysis, they often think it's going to be a lot easier than we think it's going to be. There is that kind of gap in terms of their knowledge base that they will often fill with optimistic expectations rather than the opposite. So you know we probably do need to be much clearer in terms of the outcomes...'(2)

Another nephrologist Others observed that patients often regret their decision to commence dialysis, implying that patients were not well informed prior to decision making.

It is interesting there's a recent study that showed 50\% of people on dialysis felt that they were forced onto it... We always feel that they're forcing us to put them on it so, there's a big gap out there.'(17) 
However, despite concerns about patients' understanding, the majority of nephrologists will accede to patient choice, despite clinical reservations they may have about a patient's suitability for dialysis.

'Sometimes, like, we tend to offer dialysis to anyone who wants it and who is physically able for it I think would be our bottom line, so anyone who wants it and they have support and they have said that they want to go ahead with it..'(16)

Indeed, one nephrologistSome -permitted surrogate decision makers, often family members, to choose dialysis for older relatives who lacked decision making capacity as a consequence of dementia.

..and I've had a number of people over the past couple of years with dementia and family are very keen to give them a try... I've always maintained though that it's very, very difficult to stop once you start ...... takes an aw full lot of man hours to get somebody off dialysis. The ones / have looked after would have an understanding ....they've a commitment that once they start we're going to give them six months and they all, to be honest with you everyone I have started with dementia is either still on dialysis or has died of other causes in the meantime.... those patients with dementia, they seem to get into the habit of their treatments and they just build it into their day, it gives them a day out in fact.'(10)

\section{Lack of patient centred care in patients presenting with acute severe renal failure:}

Older patients who present acutely in renal failure, often referred to as 'crash landers' in the literature, are offered dialysis by most nephrologists. The nephrologist's decision to offer dialysis is influenced by their lack of prior knowledge of the patient and uncertainty regarding the clinical outcome for patients presenting in this way.

This study suggests that dialysis has become the 'default therapy' for older patients presenting acutely with ESRD and that the relatively unlimited access to dialysis may be facilitating this practice.

'the reality is I think we are very poor at working out who will do well (dialysis ) and who won't, we think we are better than we are, am so in the acute setting I give people the benefit but I always sit with them, the family and say look we'll review it and we'll see.'(9)

'... I suppose you would always err in favour of intervention. You know we do get these crisis presentations from all over sometimes and you know if you don't know exactly what the lay of the land is we dialyse.'(10)

\section{Difficulties associated with dialysis withdrawal:}

Prior to dialysis initiation, nephrologists do not routinely discuss situations where dialysis withdrawa might be appropriate. Nephrologists perceive this as a difficult discussion to have with patients and their families as they fear it will upset patients and undermine their relationship with them Nephrologists report that many older patients continue to receive dialysis with little benefit. Often the dialysis clinical nurse specialist will highlight patients who are not thriving on dialysis but frequently, the opportunity for a timely withdrawal of dialysis is lost for many older patients.

... It's actually incredibly difficult to withdraw dialysis once you start but I think that we would all lean towards giving the patient the benefit of the doubt in this (acute) scenario unless you have a very good history that they have end stage kidney disease, that they have heart failure, dementia 
and that and there's an aw full lot of work really in talking to patients and their familyso, it's often easier to put them on dialysis, and you have to give people the benefit of the doubt....'(14)

Four $(4,10,11,8)$ Several nephrologists alluded to a sense of religious obligation experienced by patients to continue with dialysis despite little overall benefit-One nephrologist declared that and some patients fear withdrawing from dialysis will disappoint their family and nephrologist.

'...patients withdrawing, you know guilt is probably the wrong word but they don't want to let down their doctors or their family and make a decision that looks like they are actively withdrawing from that even though that would be their firm preference if it were up to them.'(8)

Most nephrologists' experience of dialysis withdrawal was with patients who were no longer thriving on dialysis and who had been admitted as a result of medical decompensation. Many of these older patients, known to have had a limited life expectancy, experienced medicalised deaths in acute hospital settings.

'Often the withdrawal will happen in an inpatient setting and am, but it's usually as a result of medical decompensation as opposed to patient wish.'(3)

'...we did a brief survey amangst our patients that have died over the last vear or wo,...in the over 75 s and although the 'surprise question' was 'no' in the majority of them, the majority of those patients still died in hospital........ you know are expecting these patients to die and to die soon, they are dying in a kind of an acute, emergency type setting which is, you know very unsatisfactory..'(2)

Most nephrologists reported / withdrawing less than five older patients from dialysis per year.

Commented [RO10]: This sounds very Dr led - was it a joint decision? Maybe were involved in five people withdrawing?

\section{2) Training deficits contribute to difficulties communicating with patients}

Nephrologists fear that discussing prognosis, dialysis withdrawal and end of life care will upset patients and compromise the doctor: patient relationship. The time required for such conversations is also perceived as a barrier to discussion. Acknowledging these factors, one nephrologist preferred to portray dialysis as a lifesaving therapy to patients.

'Partly because we think we will upset the patients and partly because we like to portray that dialysis is great and will save your life. And am partly because we're always so busy and you don't have the time to sit down and discuss these things.'(6)

Nephrologists considered older patients with extreme levels of comorbidity and technical issues precluding dialysis, as unsuitable candidates for dialysis. These patients generally were not offered dialysis. One nephrologist expressed concern that should such patients request dialysis it could be challenging to convince them of the merits of conservative management, hence, it was preferable to avoid mention of dialysis in these circumstances.

'Profound physically disability or dementia, they're people you probably wouldn't, yeah you're right I probably wouldn't offer to and I suppose sometimes being a bit cowardly would skirt away from conversation in case they said yes.'(17)

One nephrologist expressed concern that colleagues assumed what was of importance to patients and consequently, oversimplified patients' priorities. 
Ithink we overly simplify that (patients' priorities) and l'm not sure we know very well usually the answer to that question... and / think we can be guilty of assuming what it is is of importance to people..'(8)

Nephrologists also alluded to the unrealistic expectations of both patient and family as barriers to effective communication. One nephrologist observed that while many of their older and current dialysis recipients were suitable candidates for dialysis withdrawal, patient and family expectations impeded discussion of same.

'Oh / think expectations are massive and family and patient expectation are ridiculously high in Ireland.'(11)

Another nephrologistlt was also intimated that inadequate levels of shared decision making and advance care planning at the outset served as a barrier to timely dialysis withdrawal.

'So I think, you know, they're very individual conversations (dialysis withdrawal) and I think often it's unfortunate for dialysis patients because it takes them to come into hospital for these things to, for people to have these conversations....... We don't like talking about prognostication (nervous laugh)! Am I really don't think doctors like doing it....'(1)

\section{3) Nephrologists lack confidence in Conservative management}

$25 \%$ of nephrologists, working across three clinical sites, had access to a designated Low Clearance Clinics. Four (check)some-nephrologists operating at two clinical sites, operated an ad hoc Low Clearance clinic with no additional resources.

They often Three $(1,2,7)$ nephrologists-declared no confidence in conservative management as it existed at their respective clinical sites. Conservative Management was poorly resourced and poorly developed with insufficient levels of clinical expertise available and so they did not recognise it -as a legitimate treatment option for patients.

'... I don't think it (conservative management) is adequately resourced in Ireland..... It's really synonymous with little or no care and what tends to happen, is that, although the decision may be made early that someone is going for conservative pathway really when the chips are down to offer them a change of mind at a late stage and go for dialysis...... I have become a bit disillusioned with the conservative pathway however / know it's the right one to go with, with a number of patients but the problem is, because of the kind of rudimentary level...' (7) 
Four nephrologists $(2,6,7,13$-check this) -Nephrologists reported that many older patients, ideally suited to conservative management, had commenced dialysis because conservative management was not perceived as a credible treatment option at their clinical site.

'....that ( Conservative management pathway) just doesn't exist at the moment and I think that's probably why we're probably dialysing more people than we should both acute and chronic, you know. (2)'

Nephrologists perceived dialysis as a 'safety net', ensuring regular contact between older patients and the haemodialysis unit. Nephrologists alluded to a sense of moral distress and abandonment when considering the option of conservative management for older patients, who may not be seen for up to six months. The lack of clinical expertise in managing patients conservatively was perceived as a feeling of helplessness by nephrologists.

'...so I think the main barrier is that we don't see them back in clinic often enough after we have given them conservative management .... we tend to say we'll see you back in six months if you're still alive... it's almost a feeling, in my experience, that we have washed our hands of people who don't need dialysis, having said that when we do bring back people who are not going to be on dialysis we have very little to offer them..'(1)

One nephrologist, with experience of working in a successfulconservative management service abroad, acknowledged that many older patients in Ireland commenced dialysis as a default option, in the absence of an adequately resourced conservative management pathway. Many of these older dialysis recipients were therefore likely to be suitable candidates for dialysis withdrawal.

I suppose I come from the UK where we had a very wellestablished clinic, conservative care

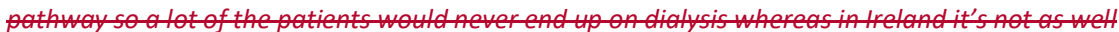
established so you mayend up needing to have these conversations a lot more in Ireland cos you maybe have patients going onto dialysis that shouldn't have gone onto dialysis at all in the first place if they were really given a proper option of conservative management.'(13)

Two nNephrologists perceived Palliative Medicine as having an integral role in the delivery of a conservative management service, thus ensuring optimal advance care planning and symptom control.

Three $(2,11,13)$ nephrologistsThey felt that patients' willingness to accept conservative management was influenced by nephrologists' experience of communicating with patients about sensitive aspects of patient care. Having the necessary communication skills to achieve this was perceived as a barrier to patients' acceptance of conservative management by two nephrologists.

..I think the barriers (to conservative management) would be maybe communication and I think if you express it in the right way to the patient or families, it's not necessarily an inferior treatment at all in the right person, you know what I mean, in fact it's probably a better treatment but you don't want the patient or family to feel that you are not doing everything that should be done, do you know what I mean? So you need to be able to have experience in having these conversations..'(13). 


\section{End of Life Care}

Nephrologists do not routinely discuss enddiscuss end of life care with older patients with ESRD. They identified time constraints and difficulties communicating with patients about dying and end of life as barriers to discussion.

'...to discuss stuff like end of life planning, your will, all that kind of stuff. You know I just don't have the time to do that and I would imagine most of us don't because we're already doing 3-4 clinics a week.'(2

f'.l'd say no, I'd say I do that badly / would say .. until they end up being admitted and the usual pressure of having something documented in their notes in the event of an acute event atherwiset think that I do that badly, I think advanced planning on that is not well done, so I don't think I'm very good at having discussions about you know...'(12)

One nephrologist observed that older patients with ESRD often experience repeated hospital admissions before they will be asked to consider their preferences for end of life care. Often these discussions occur for the first time where death is imminent eg in the context of dialysis withdrawal or where a patient was being discharged home to die.

'In the clinic it's kind of, you never really get there because you explain to them what will happen but I think in the hospital if you're talking about sending somebody home or withdrawing dialysis is kind of where you talk about it( end of life) more.'(19)

Nephrologists struggled to discuss end of life care with patients fearing that patients would perceive them as having 'given up on them.'

'And I think you often wonder then do you possibly change how the patient might feel about how you are treating them, does the patient now think they are about to die and that you have given up on them so I think there is a little bit of that as well.'(12)

-Nephrologists highlighted a lack of appropriate training and an inadequate skill set as significant barriers to communicating with patients about end of life. Some feltAnother neprologist felt that Palliative Care physicians were best placed to discuss end of life with older patients with ESRD as they are appropriately trained, more empathic and have more time than nephrologists. 
'No, it's an uncomfortable discussion and I think it's one, it really depends on the individual clinician, on how good their, I guess their emotional intelligence is and also their comfort level in having these discussions with people and tackling potentially difficult family members who don't see what you're saying or don't agree with what you're suggesting. And having the skill set and experience to deat with that, I think that's a massive barrier in this area.' (11)

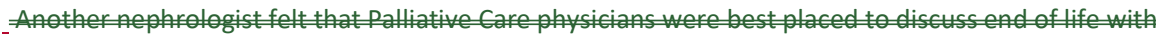

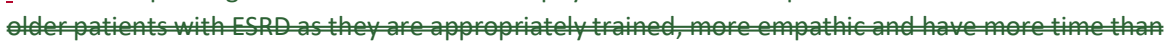
ogists.

$(4,17,18)$ Three Some nephrologists assumed that patients did not want to engage in end of life planning. One nephrologistlt was felt patients would view such a discussion negatively and that it was their responsibility to 'keep a brave face on things.' Another nephrologist felt such a discussion would cause patients 'mental anguish' and so many end of life discussions involved family members rather than patients.

'Yeah, no I don't (discuss end of life) and the barriers are the same as before in that I'm fairly familiar with all of these people and we're trying to keep a brave face on things and we start talk of dying and death and all the rest of it and 'schweeet' gone!'(4)

Of note three nephrologists referred to-deficits in communication skills among nephrology registrars, specifically in regard to patients approaching end of life were highlighted. This aspect of training is not covered by the current nephrology training curriculum.

Nephrologists alluded to a lack of experience in managing end of life care and seemed to prefer to have palliative care input at this phase of a patient's illness.

'Patients in the hospital, however, I think it's much better to have palliative in because they can have these symptoms and you'll really manage, manage death than, you know say a lot better than I think nephrologists can do although we do a pretty good job I think palliative care redirect us.'(1)

Iremember l learned an aw ful lot from her case just engaging with the family... it was actually lovely for us to see it cos we never, I never see that you know, you see that in the community.... I never got to see that whole process through with anybody really apart from her... l learned an awful lot and how to handle the family and their expectations, and her own expectations. (16)

\section{Discussion}

\section{Advanced Care Planning:}

Shared Decision Making (SDM), a component of advance care planning, is a model of medical decision making thought to support high quality patient centred care. Shared decision making ensures patients' values, wishes and preferences critically influence the decision making process and discussing the risks and benefits of individual treatment options affords patients the opportunity to make informed decisions.

Nephrologists approach to shared decision making and advance care planning in older patients with ESRD is inconsistent and needs to improve. Previous studies have highlighted low rates of ACP 
among dialysis patients ${ }^{17,23,26,28}$ in addition to the perceptions of older dialysis recipients', that nephrologists are reluctant to engage in end of life discussion ${ }^{13}$.

Prognostic uncertainty among nephrologists resulted in many avoiding this discussion with patients, mirroring clinical practice elsewhere ${ }^{14,26}$. Discussing prognosis was even discouraged by some nephrologists. Nephrologists' fear that discussing prognosis, the limitations of dialysis, dialysis withdrawal and end of life care will distress patients and jeopardise the doctor patient relationship ${ }^{14,26}$. Despite the limitations of dialysis in an older population, a number of nephrologists chose to ignore the statistics and based their decision to offer older patients dialysis on their experience of salient patients who had exceeded their life expectancy on dialysis, replicating practice elsewhere ${ }^{14}$. Many nephrologists attempted to instil hope in patients by portraying dialysis as lifesaving therapy and simultaneously circumvented any discussion of prognosis and end of life, comparable to previous studies ${ }^{14}$

In contrast to nephrologists' perceptions, older patients with ESRD report a willingness to engage in $\mathrm{ACP}$ and they expect their healthcare providers to initiate discussion ${ }^{11,17}$.Nephrologists' concern that discussing the prognosis of ESRD with elderly patients will somehow have a deleterious effect is unfounded. ${ }^{13,17} 80 \%$ of patients with chronic kidney disease want to be involved in end of life planning and they expect their clinician to broach this discussion in a timely manner ${ }^{17}$. Almost $80 \%$ of patients rely on their nephrologist for medical information but $90 \%$ of patients said their nephrologist had not discussed prognosis with them ${ }^{17} .60 \%$ of patients regretted their decision to commence dialysis with $51 \%$ reporting that it was their nephrologist's wish to initiate dialysis ${ }^{17}$

The survival benefit conferred by dialysis in older patients is limited; this benefit is lost in older patients with significant ischaemic heart disease ${ }^{3}$ (present in up to $80 \%$ REF of older patients with advanced chronic kidney disease). It is incumbent upon nephrologists to consider these statistics when contemplating dialysis in older patients, whilst acknowledging that some patients will occasionally defy the odds and exceed their predicted life expectancy on dialysis. Many older dialysis recipients will experience a deterioration in their quality of life as they adjust to the rigorous dialysis regime and the associated implications for their daily routine and that of family members ${ }^{2}$ :

Patients are generally ill informed about chronic kidney disease and the treatment options available to them ${ }^{13,24}$. Poor health literacy among older patients with ESRD contributes to patients harbouring unrealistic expectations ${ }^{13}$ and the likelihood of patients later regretting ill informed decisions is increased $^{17}$.Fundamentally, an ill-informed patient contravenes the principles of shared decision making.

Patients want to be seen 'in the context of their personal lives' by health care professionals and hence, an understanding of their illness, including prognosis and end of life, is critical to empower patients ${ }^{12}$.Well informed patients are more likely to hold realistic expectations and by understanding their illness they are empowered to establish realistic goals and live according to their values and wishes ${ }^{13}$. This enables patients to retain a sense of power over their life and enhances the prospect of maintaining hope, even in the context of a life limiting illness ${ }^{12}$. Older patients with ESRD must be invited to participate in advance care planning to maximise their opportunity of envisaging and creating a future consistent with their values

A specific group of patients highlighted in this study are those with cognitive impairment and impaired decision making capacity, in the setting of dementia. The RPA advocates a deep exploration of the benefits of dialysis to these patients ${ }^{7}$. Surrogate Decision Makers, SDM, often family members, tend to choose more aggressive medical intervention than patients themselves might 
otherwise have chosen, had they retained decision making capacity ${ }^{19}$. ACP in these situations, where a decision is made to dialyse, is critical to ensure that the dignity and well- being of the patient is preserved and that dialysis is withdrawn in a timely manner once the benefit of dialysis to the patient is no longer apparent ${ }^{7}$.

When older patients present acutely with ESRD, dialysis functions as the default therapy for most nephrologists where there is clinical uncertainty as to the likely clinical outcome. The latter is compounded by the nephrologist lacking prior knowledge of the patient and the relatively unlimited access to dialysis. ACP in the acute situation is crucial to minimise burdensome and futile medical interventions for older patients. Nephrologists testify to the challenges of withdrawing older patients from dialysis and clearly, many older patients remain on dialysis with little benefit $\underline{25}$. Dialysis initiation must be individualised following careful consideration of the patient, their expressed wishes, beliefs and values. This information is often provided by family members in the acute situation where a patient's decision making capacity may be impaired. Nephrologists need an awareness of the complexities inherent in a process where family members act as surrogate decision makers and so, to assure the welfare of these vulnerable patients, situations where dialysis withdrawal might be considered appropriate must be identified prior to dialysis initiation and the appropriateness of continuing dialysis should be reviewed regularly ${ }^{7}$.

Policy: Consideration should be given to the introduction of a mandatory document recording the key aspects of the ACP constructed by both patient and nephrologist and reflecting a careful consideration of the patients' wishes and priorities for their healthcare. This document should include resuscitation status, the ceiling of care where possible and it should be accessible to all healthcare professionals involved in the delivery of care to the patient.

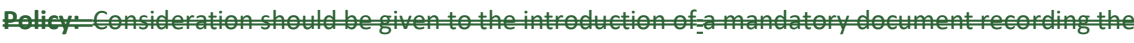

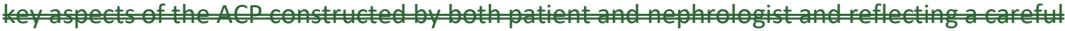

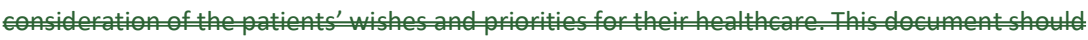

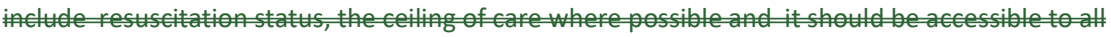

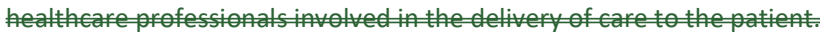




\section{Communication and end of life care}

The real barrier to communication between nephrologists and patients seems to be nephrologists' lack of confidence in their ability to discuss these emotive aspects of care reflecting a lack of training and a lack of clinical experience in having these discussions. One nephrologist stated that this training deficit meant many nephrologists had an inadequate skill set to communicate effectively with patients about dialysis withdrawal and end of life care.(11) Another nephrologist felt that colleagues oversimplified patients' priorities and made assumptions about what patients' preferences were(8), thus highlighting the implications for individual patients who were not afforded the opportunity to discuss their wishes, values and preferences with their nephrologist.

One nephrologist (20) circumvented discussion of end of life by referring patients to community based supports (GPs, Palliative care teams), thus risking the possibility that the discussion would never take place. Two nephrologists alluded to Palliative Care physicians having greater expertise, greater empathy and more time to engage with patients in regard to discussing prognosis and end of life care, reflecting a sense of resignation and inferiority in regard to this aspect of patient care.

Nephrologists who struggle with this aspect of patient care allude to a sense of personal failure and anxiety which may compromise their professional confidence and deter them from participating in future end of life planning discussions unless their learning needs are addressed ${ }^{20}$. In contrast, clinicians whose experience of ACP, including end of life planning, is positive describe it as an enriching experience' enhancing their willingness to engage in future discussion. ${ }^{20}$

Internationally nephrologists highlighted the need for formal training in communication of poor prognosis, dying and end of life care with the possibility of rotating through palliative medicine during specialty training mooted as an option for future nephrologists. ${ }^{15,16,27}$ Nephrologists' lack of training in this area undermines their ability to communicate with patients and also deprives patients of the opportunity for timely and adequate engagement in ACP. Neither should nephrologists perceive palliative medicine physicians as better equipped, and therefore more suitable, to deliver this aspect of patient care as ACP is an intrinsic component of shared decision making and so it is incumbent on all clinicians to develop their communication skills adequately to address this aspect of patient care. Hence there is an urgency to address this learning need.

Three nephrologists alluded to a sense of religious obligation, experienced by older patients, to continue dialysis despite perceived hardship and no discernible benefit. Patients confused dialysis withdrawal with suicide and euthanasia. Nephrologists must be willing to challenge patients' beliefs in this area to minimise burdensome and futile interventions. Nephrologists need to normalise dialysis withdrawal as a treatment option from the outset and situations where dialysis withdrawal might be considered should be discussed with patients prior to dialysis initiation. Changing clinical circumstances require a timely review of the appropriateness of continuing dialysis in older patients, conforming to a shared decision making process ${ }^{29}$. 
End of life care: A minority of elderly dialysis patients participate in end of life planning despite evidence of better patient centred outcomes and lower use of aggressive interventions in the last month of life $\mathrm{i}^{13,21,22}$. Older patients perceive nephrologists reluctance to engage in end of life care discussion and their fear of jeopardising the doctor patient relationship ${ }^{14}$. However they also feel that nephrologists' perceive EOL discussions as irrelevant. ${ }^{14}$

In addition to communication difficulties and time constraints, which served as barriers to engaging patients in end of life discussion, some nephrologists assumed that patients would not want to discuss or plan their death and so avoided the conversation completely. Many nephrologists felt such discussion would cause 'mental anguish' to patients and so elected to speak with family members instead. While these assumptions may reflect nephrologists' personal beliefs, over $80 \%$ of older patients want to engage in end of life planning ${ }^{17}$.

A number of nephrologists reported that end of life planning did not usually occur in the out-patient setting but instead a clinical deterioration which necessitated a hospital admission 'and the usuat pressure of having something documented in their notes' (12) sufficed. This approach increases the likelihood of an acutely unwell patient being unable to participate in end of life planning; it also increases the chances of patients experiencing medically intensive end of life scenarios and a death at variance with their wishes.

Policy: Formal training in communication with patients should form part of the nephrology specialty training curriculum and consideration should be given to incorporating a rotation in palliative medicine as part of the core curriculum. Nephrologists and doctors undergoing specialist training may also benefit from participating in joint consultations, between Nephrology and Palliative Medicine, when meeting with patients and their families.

\section{Conservative Management}

Conservative Management as it currently exists, is considered by many nephrologists as an inferior therapeutic option, 'synonymous with little or no care' (7). The service is poorly resourced and many nephrologists referred to a lack of clinical expertise amongst nephrologists. Three nephrologists, disillusioned with the service, encouraged patients to choose dialysis rather than conservative management, despite patients' perceived suitability for the latter ${ }^{14}$.

Nephrologists struggled to define their role in the delivery of conservative management and alluded to a sense of moral distress and helplessness when contemplating it as an option for patients, reflecting previous findings ${ }^{14}$. Similar studies report that many nephrologists equated conservative management with 'imminent death', thus belying their desire to instil hope in patients ${ }^{14}$. In this study, a number of nephrologists preferred the 'safety net' offered by dialysis, which ensured regular contact between patients and the haemodialysis unit.

Little is known of nephrologists' perception and acceptance of conservative management in centres where the service is well resourced. Interestingly, nephrologists who universally offer conservative management to older patients experience less moral distress than those who do so sporadically ${ }^{14}$. It is possible that the relatively unlimited access to dialysis is impeding the development of a wellresourced conservative management service at various clinical sites. 
Policy: The key components of a successful conservative management pathway include comprehensive advance care planning, clinical expertise in the medical management of ESRD, including recognition of the diverse and complex symptom burden of ESRD in older patients, and a multidisciplinary team capable of delivering a service which is both accessible to patients and resourced to meet their needs. Establishing such a service requires effective leadership, resource investment and an ethos based on patient centred care as its core value which will ultimately achieve better patient outcomes ${ }^{14}$. 
Table 1. Characteristics of Nephrologists

*Nephrologists may have completed more than one international fellowship during training

\begin{tabular}{|c|c|c|}
\hline \multicolumn{2}{|l|}{ Variable } & $\%(n)$ \\
\hline \multirow{2}{*}{ Gender } & Male & $60 \%$ (12) \\
\hline & Female & $40 \%(8)$ \\
\hline \multirow{4}{*}{ Years since Medical School Graduation } & $<15$ yrs & $10 \%(2)$ \\
\hline & $15-20$ yrs & $15 \%(3)$ \\
\hline & 20-30yrs & $65 \%(13)$ \\
\hline & $>30 y r s$ & $10 \%(2)$ \\
\hline \multirow{2}{*}{ Nationality } & Irish & $95 \%(19)$ \\
\hline & Other & $5 \%(1)$ \\
\hline \multirow{4}{*}{ International |Fellowships* } & USA & 14 \\
\hline & Canada & 1 \\
\hline & UK & 7 \\
\hline & Australia & 3 \\
\hline \multirow{3}{*}{ Healthcare Setting of Clinical Practice } & Public & $65 \%(13)$ \\
\hline & Private & $0 \%(0)$ \\
\hline & Mixed & $35 \%(7)$ \\
\hline \multirow{2}{*}{ Designated Low Clearance Clinic } & Yes & $25 \%(5)$ \\
\hline & No & $75 \%(15)$ \\
\hline \multirow{2}{*}{ Access to Local Palliative Care Services } & Yes & $100 \%(20)$ \\
\hline & No & $0 \%(0)$ \\
\hline
\end{tabular}

Commented [SA22]: People can have done $>1$, correct? Maybe we should say that here as everything else are mututally exclusive categories?

Commented [SA23]: These aren't 


\section{References}

1 Hole B. Treatment of end stage kidney failure without renal replacement therapy. Semin Dialy 2016; 29:491-506

2 Da Silva-Gane M, Wellstead D, Greenshields H, Norton S, Shand na SM, Farrington K. Quality of life and survival in patients with advanced kidney failure managed conservatively or by dialysis. Clin J Am Soc Nephrol 2012;7: 2002-2009

3 Murtagh F. Dialysis or not? A comparative study of patients over 75 years with chronic kidney disease stage 5.Nephrol Dial Transplant 2007 ;22: 1955-1962

4 ERA EDTA Registry. ERA EDTA registry annual report 2011. Amsterdam, Academic Medical Centre, Department of Medical Informatics, 2013.

5 Chan KE, Maddox FW, Tolkoff- Rubin N et al. Early outcomes among those initiating chronic dialysis in the United States. Clin J Am Soc Nephrol 2011;6:2642-2649

6 Carson RC, Juszczak M, Davenport A, Burns A. Is maximum conservative management an equivalent treatment option to dialysis for elderly patients with significant comorbid disease? Clin J Am Soc Nephrol

7 The Renal Association. Clinical practice guidelines for the planning, initiation and withdrawal of renal replacement therapy. 2014. Available from http://www.renal .org/guidelines. Accessed

\section{Find one}

9 Wachtermann MW, Mercantonio ER, Davis RB, Cohen RA, Waker SS et al : Realtionship between the prognostic expectations of seriously ill patients undergoing haemodialysis and their nephorlogists. JAMA Intern Med 173 :1206-1214 2013

10 Wong SP, Kreuter PW, O' Hare AM. Treatment intensity at the end of life in older adults receiving long term dialysis. Arch Intern Med 172:661-663, 2012

11 Davison SN, Kromm SK, Currie GR. Patient and health professional preferences for organ allocation and procurement, end of life care and organisation of care for patients with chronic kidney disease using a discrete choice experiment. Nephrol Dial Transplant 25: 2334-2341 2010

12 Davison SN, Simpson C. Hope and advance care planning in patients with end stage renal disease. Qualitative interview study. BMJ 333: 886, 2006

13 'End of life Care? I'm not going to worry about that yet' Health Literacy Gaps and End of life Planning Among Elderly Dialysis Patients. Ladin Keren, Buttafarro Katie, Hahn Emily, Gerontologist 2017 Vol 00 No 00 1-10. 
14 Discussing Conservative Management With Older Patients With CKD: An Interview Study of

Nephrologists KerenLadin ${ }^{12}$ RenukaPandya ${ }^{2}$ AllisonKannam ${ }^{2}$ RohiniLoke ${ }^{2}$ TiraOskoui ${ }^{2}$ Ronald

D.Perrone ${ }^{3}$ Klemens B.Meyer ${ }^{3}$ Daniel E.Weiner ${ }^{3} J$ ohn B.Wong ${ }^{3}$ American Journal of Kidney Diseases, Volume

71, Issue 5, May 2018, Pages 605-607

15 Update on End of Life Care Training During Nephrology Fellowship: A Cross Sectional National Survey of Fellows. Coombs, Sara, Culp Stacey, Matlock Daniel D, Kutner Jean S, Holley Jean L, Am J Kidney Dis February 2015 65(2) 233-239

16 'Nephrologists' Reported Preparedness for End of life Decision-Making.' Davison, SN, Jhanghri JS, Holley JL, Moss AH, Clin J Am Soc Nephrol 1:1256-1262, 2006

17 'End of Life Care Preferences and Needs: Perceptions of Patients with Chronic Kidney Disease.' Davison, SN, CLin J Am Soc Nephrol 5: 195-204, 2010

CHECK 18 'The evolving concept of health literacy. Social Science and Medicine 1982 67, 2072-2078, Nutbeam 2008,

19 Meeker MA, Jezeweski MA'Family decision making at end of life.' Palliative Supportive Care 3: 131-142, 2005

20 Clinicians' perspectives on Advance Care Planning for patients with CKD in Australia: AN Interview Study. Sellars, M, Tong Alison, Luckett T, Morton RL, Clayton, J AJKD 2017;(70)(3) 315-323

21 Nephrologist- facilitated advance care planning for haemodialysis patients: A qualitative improvement project. American Journal of Kidney Diseases, 68, 103-109, ajkd.2015.11.024

22 Detering, K. M Hancock, A,D Reade,M, C \& Silvester, W (2010). The impact of advance care planning on end of life care in elderly patients. Randomised controlled trial, BMJ, 340,,c1345.doi: 10.1136/bmj.c1345

23 Holley JL: Advance care planning in CKD/ESRD: An evolving process. Clin J Am Soc Nephrol 7: 1033-1038, 2012

24 Tonkin- Crine S, Okamoto F, Leydon GM, Murtagh FE, Farrington K,' Understanding by older patients of dialysis and conservative management for chornic kidney failure,' Am J Kidney Dis, 2015 $\operatorname{Mar}(65) 3443-50$

25 Am J Kidney Dis. 2017 Nov;70(5):602-610. doi: 10.1053/j.ajkd.2016.12.015. Epub 2017 Feb 24.

'System-Level Barriers and Facilitators for Foregoing or Withdrawing Dialysis: A Qualitative Study of Nephrologists in the United States and England. Grubbs V1 $, \underline{\text { Tuot DS }}{ }^{2}, \underline{\text { Powe NR }}{ }^{2}, \underline{\text { O'Donoghue D }^{3}}$, ${\text { Chesla } \mathrm{CA}^{4}}^{4}$

26 Health Expect. 2017 Apr;20(2):260-273. doi: 10.1111/hex.12454. Epub 2016 Mar 10.'End-of-life care decisions for haemodialysis patients - 'We only tend to have that discussion with them when they

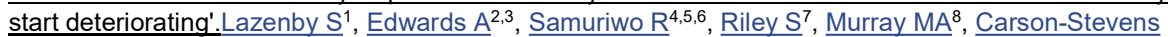
$\underline{\mathrm{A}}^{3,9,10}$. 
27 Nephrol Dial Transplant. 2015 Dec;30(12):1951-8. doi: 10.1093/ndt/gfv284. Epub 2015 Aug 12.'Nephrologists' perceptions regarding dialysis withdrawal and palliative care in Europe: lessons from a European Renal Best Practice survey.'van Biesen $\mathrm{W}^{1}$, van de Luijtgaarden $\mathrm{MW}^{2}$, Brown $\mathrm{EA}^{3}$, Michel $\mathrm{JP}^{4}$, van Munster $\mathrm{BC}^{5}$, Jager $\mathrm{KJ}^{2}$, van der Veer $\mathrm{SN}^{6}$

28 Clin J Am Soc Nephrol. 2017 Nov 7;12(11):1762-1770. doi: 10.2215/CJN.03830417. Epub 2017 Sep 18.'Nephrology Provider Prognostic Perceptions and Care Delivered to Older Adults with Advanced Kidney Disease.'Salat $\mathrm{H}^{1,2}$, Javier $\mathrm{A}^{1,2}$, Siew ED ${ }^{1,2}$, Figueroa $\mathrm{R}^{3}$, Lipworth $\mathrm{L}^{2,4}$, Kabagambe

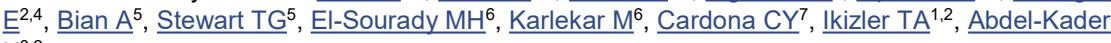
$\underline{\mathrm{K}}^{8,2}$.

29 BMC Nephrol. 2017 Jun 19;18(1):200. doi: 10.1186/s12882-017-0617-3.'Treatment decisions for

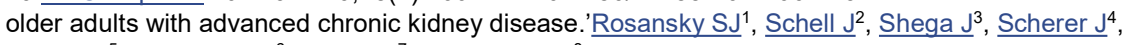
Jacobs $L^{5}, \underline{\text { Couchoud } C^{6}}$, ${\underline{\text { Crews } D^{7}}}^{7} \underline{\text { McNabney }}^{8}$. 